\title{
Girardin: abolicionismo entre el segundo imperio y la tercera república francesa ${ }^{1}$
}

\author{
Eugenio Raúl Zaffaroni²
}

\begin{abstract}
Resumen: El artículo trata de mostrar la actualidad del pensamiento criminológico del periodista francés Émile Girardin. El autor, aunque originário del siglo XIX, desarrolla una tésis penal de carácter abolicionista, con un elevado grado de actualidad, no solo con respecto a las actuales tesis penales, contrárias al poder punitivo estatal, sino también con respecto al dearrollo de un Estado Previdente, necesário para la paulatina abolición de las penas.
\end{abstract}

\begin{abstract}
The article tries to show the current criminological thinking of the French journalist Emile Girardin. The author, although originating in the nineteenth century, develops a thesis penal abolitionist character with a high degree of actuality, not only with regard to the existing penal theory, contrary to state punitive power, but also with respect to a State development Previdente necessary for the gradual abolition of penalties.
\end{abstract}

1. Cuando hoy se habla de abolicionismo penal para señalar al conjunto de corrientes que pretenden la abolición del poder punitivo, suelen indicarse como antecedentes a anarquistas y socialistas del siglo XIX e incluso del XVIII, pero no se menciona la contribución de gran valor de un autor que no estuvo afiliado a esas corrientes políticas sino que, por el contrario, estuvo más cerca de posiciones conservadoras, hasta el punto de ser considerado con cierto grado de oportunismo político.

\footnotetext{
1 Con gusto nos sumamos al justísimo homenaje a Claus Roxin con un tema que, aunque parezca lejano de sus preocupaciones, no es para nada ajeno a sus amplias inquietudes intelectuales. Para probarlo remitimos a su trabajo Ha un futuro il diritto penale?, en "Critica del diritto", n 4, 1998, p. 232.

2 Departamento de Derecho Penal y Criminología. Facultad de Derecho. Universidad de Buenos Aires. Julio 31 de 2001.
} 
Se trata de Émile de Girardin, que escribió un libro abolicionista muy singular en 1868 y lo publicó en $1871 .^{3}$

Girardin fue un periodista francés, que nació en París en 1806 y murió en la misma ciudad en 1881. Escribió varias obras de teatro, incluso una en colaboración con Alejandro Dumas (h). En 1836 fundó La Presse, que fue el primer diario de gran tirada y bajo precio, que sostuvo a Thiers hasta $1846 .{ }^{4}$ Precisamente, la prensa moderna de gran tirada se inaugura con el diario fundado por Girardin, que gracias a los pequeños anuncios y a la publicidad, era vendido a mitad de precio que los otros diarios. Fue, por ende, el iniciador de la prensa moderna, lo que suscitó serias polémicas en el mundo periodístico. Armand Carrel, fundador del National en 1830 y convertido en militante republicano, se consideró ofendido porque un periodista convertía al periodismo en una cuestión comercial, por lo que retó a duelo a Girardin, perdiendo la vida en el encuentro. ${ }^{5}$

Girardin fue diputado en 1834 y en 1849 miembro de la asamblea legislativa. Fue expulsado después del golpe de estado del 2 de diciembre de 1851 y a su regreso a Francia retomó la publicación de La Presse y fundó el diario La liberté, donde se erigió en defensor del imperio liberal, para luego sostener el gobierno de Thiers en Le Moniteur universel y Le petit Journal y atacar seguidamente a Mac-Mahon y De Broglie en La France. Estaba casado con una célebre escritora: Delphine Gay (1804-1855).

Su libro abolicionista de 1871 es citado muy pocas veces. Matteotti lo recuerda como uno de los pocos que no sólo deslegitimó la agravación por reincidencia, sino que se animó a negar directamente el derecho de punir. ${ }^{6}$ Creemos que es conveniente quitarle el polvo a este viejo libro, porque destacando la posición abolicionista de alguien que no tiene vínculos con el pensamiento anárquico y utópico se desarma el mito de

\footnotetext{
3 Èmile de Girardin, Du droit de punir, París, Henri Plon, 10, rue Garancière, 1871, 440 páginas.

4 Guy Antonetti, Histoire contemporaine politique et sociale, París, 1986, p. 239.

5 Idem, p. 260; también: Pierre Pellicier, Emile de Girardin, París, 1985.

6 Giacomo Matteotti, La recidiva, Saggio di revisione critica con dati statistici, Milano, 1910 , p. 240.
} 
que la deslegitimación del poder punitivo es sólo una cuestión de autores de esas tendencias en el siglo XIX, y de nórdicos europeos de la segunda mitad del siglo XX. Con Girardin nos hallamos ante un político francés, periodista de singular éxito, que lo sostiene con argumentos que hoy en parte pueden parecer curiosos, pero que en otra parte no son más que los de un liberal asombrado frente al devastador panorama que presentan las características estructurales del ejercicio de la represión penal. En la portada del libro, bajo el título, aparece el grabado de un crucifijo, lo que en el texto se explica, al considerar a Jesucristo como la víctima más destacada del poder que deslegitima y menta como inútil en sus páginas.

Desde que el libro fue publicado, hace exactamente ciento treinta años, sólo han cambiado las circunstancias variables del poder punitivo, pero sus trazos estructurales se mantienen inalterados - como no puede ser de otro modo - y a su respecto las observaciones del autor conservan toda vigencia y su texto es a veces de notable frescura y actualidad.

2. El planteamiento es bien coherente y se abre con una reflexión sobre la libertad que ocupa casi todo el prefacio. Recuerda una vieja polémica de 1850, en que sostuvo que entre la libertad de decir de todo y la de hacer de todo existe una enorme diferencia, porque nada tiene que ver el decir con el hacer. Expresa que inmediatamente tuvo grandes dudas al respecto y veinte años más tarde - al tiempo de escribir el libro -, está convencido de que la libertad es una e indivisible. Si la libertad de pensar implica la libertad de decir, la libertad de decir implica la libertad de hacer. ¿Debo admitir entonces la libertad de hacer el mal? ¿Y por qué no la he de admitir, si después de haber admitido la libertad de pensar mal, admito la de mal decir? ¿Pero entonces, en qué deviene la sociedad?7 Esta es la cuestión que pensó durante veinte años, para concluir que la libertad es única e indivisible y que cuando se la quiere dividir, cesa la libertad y aparece la arbitrariedad. ${ }^{8}$

Afirma que llega a esa conclusión como resultado de lo que hoy llamaríamos relativismo cultural y que en sus palabras considera testimonio de la historia: lo que se prohibe en un país no se prohibe en otro; lo que

7 Girardin, 1871, p. 3.

8 Idem, p. 5. 
una religión santifica otra condena; lo que bajo una denominación es crimen deja de serlo con un cambio de nombre. Y agrega que esto último sucede con los homicidios y los robos colectivos conocidos con el nombre de guerra. ¿Acaso los homicidios y los robos individuales hacen correr más sangre que los colectivos a los que se les levantan arcos de triunfo? Sostiene que si la guerra y la conquista no existiesen, seguramente se sostendría que son incompatibles con el estado de sociedad, o sea que, si la sociedad existe con semejante impunidad, también existiría con la del homicidio y del robo individual. ${ }^{9}$ La sociedad sin la guerra no perdería mano de obra en servidcio militar, los impuestos bajarían muchísimo, la deuda pública se amortizaría rápidamente y la sociedad sería el reino de la ciencia, de la libertad, de la producción y de la riqueza, en vez de serlo de la violencia, de la opresión, de la destrucción y de la miseria. ${ }^{10}$ Cuando la guerra y la conquista cierren sus escuelas de muerte y robo, el bienestar general haría que los delitos de homicidio y robo en el plano individual resulten completamente raros.

Es notoriamente actual la observación de que nadie querrá robar cuando gane con su trabajo más de lo que gane con el robo. Si el robo no fuese penado, quien robase impunemente podría a su vez ser impunemente robado ¿cuál sería entonces la ventaja de robar? ${ }^{11} \mathrm{Si}$ el robo dejase de alimentar los homicidios, éstos se reducirían a unos pocos casos de delirio. $^{12}$

Reafirma que las tres libertades (de pensar, de decir y de hacer) son inseparables, porque la libertad de pensar no consigue sin la de decir, que es necesaria para demostrar el error, y ésta no es concebible sin la libertad de hacer para verificar la inconsecuencia. El acto es necesario para verificar la palabra, tanto como ésta lo es para verificar el pensamiento. ${ }^{13}$ Esta libertad es indispensable para que el hombre aprenda a pensar bien, y quien piensa bien no actúa mal: nadie pretende que 2

\footnotetext{
9 Ibidem.

${ }^{10}$ Idem, p. 6.

11 Ibidem.

12 Idem, p. 7.

13 Idem, p. 8.
} 
más 2 sean 5, cuando sabe que son 4. De este modo se hace al hombre a la imagen de la civilización. No debeis penar al hombre sino instruirlo. ${ }^{14}$ Es por la transformación de la sociedad que se transformará el hombre. ¿Cuál será esta transformación? Responde que será la que prescriba la lógica, para que el reino de la libertad indivisible sea el reino de la razón humana. ${ }^{15}$ Se pregunta si esa transformación se realizará violentamente y de golpe o científica y progresivamente, y responde inclinándose por la última alternativa, que hoy se definiría como reformista. No es Girardin un irreflexibo utópico, sino que se percata del largo camino a recorrer, observando resignadamente que la justicia de una idea es independiente de los medios de su aplicación: que el vapor sea una fuerza es una cosa, pero encontrar quien invente la caldera y no se amilane ante las explosiones y fracasos es otra. Defender la idea de que el hombre, hermano del hombre, no tiene el derecho de penarlo, que la sociedad no tiene derecho a emplear los medios bárbaros que usa y que hay medios mejores para contener al idiota o al insano, implica provocar una primera reacción de incredulidad, que dará lugar a la reflexión que generará objeciones, las que, a su vez, engendrarán las soluciones. ${ }^{16} Y$ cuando la sociedad viva sin carceleros ni verdugos, con menos homicidas y ladrones, parecerá tan simple como hoy lo es su existencia sin esclavos ni siervos, pese a que, durante siglos, se haya pretendido que eso era absolutamente imposible. ${ }^{17}$ En consecuencia, sostiene que publica el libro sin la menor esperanza de asistir al triunfo de sus ideas, pero con la de apelar a la meditación de los pensadores y a la controversia de los publicistas sobre la más importante cuestión de su tiempo, que era el fundamento de la libertad. ${ }^{18}$ Con cierto grado de omnipotencia confía en que el sólo poder de la verdad de su idea regenerará el mundo después de su muerte. Como corresponde a un pensamiento relativamente conservador, aclara que no critica por criticar, que jamás critica una institución existente sin pensar por cuál debe ser sustituída, que si cuestiona la legitimidad del derecho de punir, lo hace

\footnotetext{
14 Idem, p. 9.

15 Idem, p. 10.

16 Idem, p. 12.

17 Ibidem.

18 Idem, p. 13.
} 
para saber cómo sustituir una rueda defectuosa del aparato social por otra que sea más simple y fuerte, y que intenta ser a la libertd lo que Watt y Fulton fueron al vapor: no los descubridores, sino simplemente los que utilizaron su fuerza. ${ }^{19}$ La libertad ha conquistado el derecho a pensar y poco más tarde conquistó el derecho a decir y a imprimir lo que se piensa; pero está incompleta, pues falta a su plenitud el derecho de hacer, sin otro límite que la razón ejercida mediante el razonamiento. ${ }^{20}$ Culmina aristotélicamente respecto de la reforma que propone: ni timidez ni temeridad. ${ }^{21}$

3. En el primer capítulo (De la servidumbre penal) demuestra que la pena es un resabio de la esclavitud. Las penas corporales, las penas aflictivas, son el último anillo de la larga y pesada cadena de la esclavitud, por lo que justamente se las llama la "servidumbre penal". 22 Girardin no es precisamente un tímido, pues manifiesta que con este libro continúa la obra de Beccaria, quien se había quedado corto al limitar la servidumbre penal, por lo que ahora es él quien se encarga de perfeccionar su deslegitimación, ahora contra toda la servidumbre penal. La penalidad tiene origen servil. En Roma el ciudadano libre que había desafiado la severidad de la ley era declarado esclavo de la pena, "servus poenae". Esta esclavitud le despojaba de su inviolabilidad..$^{23}$ Con este recurso el poder punitivo romano aplicaba a los ciudadanos las penas de los esclavos. En Francia la asimilación del noble al siervo para los mismos fines se produjo progresivamente.

Girardin cita a Du Boys ${ }^{24}$ para reafirmar que el origen de la pena era la satisfacción de un deseo de venganza. Dice que a la venganza sigue la composición, reconociendo que esta última tiene un efecto pacificador y que importa una reconciliación, que el asilo medieval era una imitación del asilo griego y romano y que el rigor de la pena aumenta con el espíritu

19 Idem, p. 14.

20 Idem, p. 12.

21 Idem, p. 16.

22 Idem, p. 19.

23 Idem, p. 20.

24 Albert Du Boys, Histoire du Droit Criminel des peuples anciens despuis la formation des sociétés jusqu'a l'etablissement du Christianisme, París, 1845. 
de dominación. ${ }^{25}$ Hace un largo alegato contra el efecto disuasivo de la atrocidad de los suplicios, demostrando con datos históricos que donde las leyes fueron más duras los delitos se multiplicaron. Establece períodos, afirmando que hubo un momento en que no había punición en Europa y todo era venganza privada, un segundo momento en que las penas fueron crueles y un tercero en que éstas se dulcificaron, que sería el de Beccaria; propone un cuarto, en que las penas deben desaparecer. Es interesante señalar que esta periodización coincide en general con la usada por el positivismo criminológico pocos años más tarde, especialmente por Ferri, y repetida hasta hoy (venganza privada, venganza pública, humanización $\mathrm{y}$, para los positivistas ferrianos, el período científico, reemplazado por Girardin por la desaparición).

Observa que Beccaria defiende el derecho de punir en nombre de la utilidad, y afirma que en nombre de la misma (más que de la justicia) habrá de negarlo. ${ }^{26}$ Sostiene que la penalidad corporal es el mayor obstáculo que la civilización ha encontrado en su curso, ${ }^{27}$ al punto de citar la crítica a la esclavitud formulada por Montesquieu y afirmar que es completamente válida respecto de la esclavitud penal. Concluye, pues, en que la pena no puede justificarse por su legitimidad ni por su utilidad. ${ }^{28}$

4. En el segundo capítulo (De la legitimidad del derecho de punir) se ocupa de los argumentos que hacen a la deslegitimación de la pena. Fuera del estrecho marco de la legítima defensa - afirma -, la sociedad no reconoce al hombre el derecho de punir a otro. Si el derecho de punir no lo tiene el hombre ¿a qué título lo ejercerá la sociedad? Si la sociedad lo recibe de Dios, que comience por demostrar la existencia de Dios y luego pruebe que éste le ha delegado ese derecho. Si la sociedad no lo tiene más que por ella misma, dada la forma en que lo ejerce ¿cómo osará legitimar la posesión para el uso? Si este uso no ha sido más que un largo y cruel abuso, más útil a la barbarie y a la opresión que a la civilización y a la libertad ¿sobre qué habrá de fundarse su legitimidad?

$\begin{array}{ll}25 & \text { Idem, p. } 24 . \\ 26 & \text { Idem, p. } 30 . \\ 27 & \text { Idem, p. } 31 . \\ 28 & \text { Idem, p. } 31 .\end{array}$

Revista Seqüência, no 59, p. 193-218, dez. 2009. 
Nada atestigua esta legitimidad, pero todo constata este abuso. No hay una página de la historia que no la haya manchado de sangre. ${ }^{29}$ ¿Qué es la historia sino el sangriento martirológio de innumerables víctimas inmoladas por la ignorancia, la superstición, al tiranía, la crueldad, la iniquidad, armadas del derecho de punir? Agrega que para negar estas dudas sería necesario resucitar de sus tumbas a los inmortales culpables, a la cabeza de los cuales está Jesucristo. Rechaza frontalmente el argumento del contrato social (Beccaria, Hobbes, Locke, Vattel) ${ }^{30}$ y también que el derecho de punir deriva de la legítima defensa (Blackstone, Romagnosi, Carmignani), ${ }^{31}$ al igual que la tesis de la defensa social (Beccaria, Rossi), afirmando que la sociedad se defiende mejorando las cosas y no apelando a la violencia reproductora. ${ }^{32}$ A la tesis reaccionaria - pero no por ello omitida en el pensamiento no expreso de muchos bienpensantes de nuestro tiempo - de Leibnitz y Joseph De Maistre, que deducen la legitimidad de la expiación, responde, entre otras cosas, que las deformidades morales existen en la naturaleza de igual modo que las físicas, pero se pregunta cómo puede pretender expiación el estado que glorifica bajo los nombres de guerra y conquista lo mismo que sanciona en los individuos. Si el servicio militar obligatorio no es más que la instrucción obligatoria al asesinato bajo pena de fusilamiento para quien se rehuse, la guerra es la escuela de todos los crímenes y de todos los excesos. Matar a un hombre y robarle su dinero es un acto criminal penado por la justicia. Matar quinientos mil hombres y robarles el suelo sobre el que han nacido es un acto glorioso inmortalizado por la historia. ${ }^{33}$ Si el crimen se pena en el individuo, nadie pena los crímenes cometidos de estado a estado ni de pueblo a pueblo, no hay expiación a su respecto: ¿Con qué autoridad la sociedad podrá exigir la expiación si ella es más culpable? La única expiación que admite es la reparación, que en el robo es restitución, pero la libertad que se le quita al ladrón no restituye el dinero a la víctima

\footnotetext{
29 Idem, p. 32.

30 Idem, p. 34.

31 Idem, p. 36.

32 Idem, p. 40.

33 Idem, p. 41.
} 
ni la vida que se le quita al homicida devuelve la vida a la víctima. ${ }^{34} \mathrm{~A}$ Guizot y Cousin, que sostienen que la legitimidad proviene de la justicia, responde que para eso la justicia debiera ser única y universal y no local, de modo que lo que es delito en un país no lo es en otro. ¿Qué se puede decir de la justicia que quemaba a los heréticos y a los magos? ¿Qué cabe pensar de la justicia que pena a los pensadores del mismo modo que a los ladrones? ¿Cómo calificar a la justicia que condenó, suplició, mató, crucificó, quemó, sometió a la rueda, descuartizó, aprisionó o exiló a los mayores filósofos, a los más célebres escritores, a los más ilustres sabios? ${ }^{35}$ La justicia es expresión de la sociedad, pero ésta no es expresión de la humanidad. Decir que la punición es una forma de la justicia es un sinsentido, pues la justicia de la sociedad puede ser la forma de la iniquidad humana y la máscara de la barbarie. ${ }^{36}$ Se ocupa luego del talión kantiano, considerándolo un argumento pobre para un filósofo de la talla de Kant, y negando su legitimidad también en base a la arbitrariedad de las leyes sociales. ${ }^{37}$ Como resultado de este paseo por las tesis legitimantes, concluye en la ilegitimidad del derecho de punir y, por ende, pasa a preguntarse por su utilidad.

5. En el capítulo tercero (De la utilidad del derecho de punir) adelanta la opinión de que las penas no tienen utilidad alguna, con la curiosa afirmación - sobre la que volverá más específicamente en varias ocasiones - de que la única pena que realmente tendría utilidad sería la pena de muerte. Por ello, sostiene que tendría razón de Maistre y no Beccaria, que cae en un cuadro de contradicciones: Lógicamente, es Beccaria, el crítico de la pena de muerte, quien está equivocado, y es Joseph de Maistre, el apologista del verdugo, quien tiene razón. Beccaria es la inconsecuencia, pues todas sus proposiciones se contradicen; pero de Maistre es la impostura, pues supone un Dios que no existe, un Dios creador ardiente de impaciencia, desenfrenado de cólera, castigando a su criatura. ${ }^{38}$ Yo no admito ni la media penalidad según Beccaria ni la doble

$\begin{array}{ll}34 & \text { Idem, p. } 42 . \\ 35 & \text { Idem, p. } 43 . \\ 36 & \text { Idem, p. } 44 . \\ 37 & \text { Idem, p. } 46 . \\ 38 & \text { Idem, p. } 51 .\end{array}$

Revista Seqüência, no 59, p. 193-218, dez. 2009. 
penalidad según de Maistre. Digo: doble penalidad, pues la condenación pronunciada por un Dios que juzga a los hombres después de la muerte, si se acumula con la condenación del hombre juzgado por el hombre, constituye un pleonasmo que viola el principio "non bis in idem". Quien afirma la inocencia del verdugo niega la existencia de Dios; quien afirma la existencia de Dios niega la inocencia del verdugo. El mismo culpable no puede ser justamente penado dos veces por la misma falta, la primera antes de su muerte y la segunda después de ésta. Joseph de Maistre no es un cristiano sino un pagano. ${ }^{39}$

Se hace cargo de la situación de estigmatización social que pesa sobre los liberados para desacralizar la eficacia de la pena privativa de libertad y hacer resaltar la paradoja de que la única pena con real efecto preventivo especial negativo, sería la de muerte. Si no se puede probar la utilidad de la punición, habiendo usurpado la sociedad el nombre de la justicia para desarmar al hombre ¿no será llegado el tiempo en que el hombre desarme a la sociedad en el merecido nombre de la ciencia? ${ }^{40}$

6. En el cuarto capítulo (La escala penal) Girardin pasa revista a las penas del código de Napoleón ${ }^{41} \mathrm{y}$ cita autores que critican su inútil complejidad. A efectos de su análisis, las reclasifica en cinco categorías: penas de privación de la vida, de la libertad, de la patria, de los derechos cívicos, civiles y de familia y de una suma de dinero. ${ }^{42}$ En el capítulo quinto (De la privación de la vida), insiste en su curiosa afirmación acerca de la pena de muerte, aclarando que es contrario a la misma, pero que antes de suprimirla debiera ser suprimida la pena privativa de la libertad, o sea que su abolicionismo ascendería en la escala penal en lugar de descender. ${ }^{43}$ Sostiene que las ventajas de la pena de muerte son que no pervierte, no deprava, no corrompe al inmenso personal necesario para la ejecución, no incrementa el crimen, etc. En cuanto a su carácter irreparable considera que tampoco es reparable la pena de trabajos

\footnotetext{
39 Idem, p. 52.

40 Idem, p. 57.

41 Idem, pp. 58-59.

42 Idem, p. 61.

43 Idem, p. 63.
} 
forzados que enferma y mata. ${ }^{44}$ Destaca la contradicción entre considerar tan valiosa la vida de un inocente y admitir sin problema que los estados las destruyan tan fácilmente por un pequeño conflicto de territorio. $\mathrm{Si}$ bien observa que la pena de muerte ha sido abolida en varios países y que su aplicación es cada vez menos frecuente en Francia, concluye que es adversario de toda pena corporal y no sólo de la pena de muerte, y que a ésta la mantendría temporariamente y para los homicidios exclusivamente después de la desaparición de las restantes penas y hasta la total extinción del poder punitivo. ${ }^{45}$

7. En el capítulo sexto (De la privación de la libertad), analiza el complicado sistema de penas privativas de libertad del código Napoleón y formula la crítica de cada uno de ellos, comenzando por los trabajos forzados a perpetuidad, que considera la esclavitud penal por excelencia. ${ }^{46}$ Se extiende largamente contra la pena de deportación, mostrando su fracaso no sólo en el caso francés sino también en el de Australia, ${ }^{47}$ lo que parece ser un tema reiterativo en la literatura penal de su tiempo, dada la primitiva confianza depositada en esta pena como sustitutivo penal. ${ }^{48}$ En cuanto a la pena de trabajos forzados temporales, dice que la entiende aún menos que los perpetuos. Sostiene que los presidios son la escuela superior del crimen, de modo que la sociedad es increiblemente contradictoria manteniendo un escalón penal que en lugar de contener al crimen lo estimula. ${ }^{49}$ En cuanto a la reclusión, que es una pena por la que se encerraba en una maison de force al condenado entre cinco y diez años, dice que es la escuela preparatoria de la prisión. ${ }^{50}$ Largamente se extiende sobre las consecuencias de la prisión, sobre el régimen, sobre la nunca resuelta cuestión de los liberados que reinciden como resultado de

\footnotetext{
44 Idem, p. 65.

45 Idem, p. 75.

46 Idem, p. 82.

47 Idem, p. 113.

48 V. por ejemplo, en 1875, el trabajo de Concepción Arenal, Las colonias penales de la Australia y la pena de deportación, publicado en sus Obras Completas, Madrid, 1895, Tomo X.
49 Girardin, 1871, p. 114.
50 Idem, p. 117.


su estigmatización social, ${ }^{51}$ y concluye que la pena privativa de libertad no es más que una pena de muerte ejecutada lentamente, concluyendo en la necesidad de su desaparición. ${ }^{52}$

8. En el capítulo séptimo (De la privación de la patria), critica la pena de deportación con la sagaz observación de que si Francia puede enviar a sus malhechores fuera de su territorio, tendría el deber de recibir a los ajenos en el suyo. ${ }^{53}$ No está de más recordar que en los tiempos de Girardin la Argentina enviaba delincuentes al Paraguay. En el capítulo octavo (De la privación de los derechos cívicos, civiles y de familia) sostiene que es indefendible la privación de la condición de ciudadano y afirma que son penas innecesarias, cuya función podría cumplir igualmente la publicidad. ${ }^{54}$ En el capítulo noveno (De la privación de una suma de dinero) se ocupa de la multa y de la reparación del daño. En cuanto a la primera destaca su inequidad y, en cuanto al resarcimiento, recuerda con admiración las viejas disposiciones inglesas que obligaban a la reparación a la comuna de origen del delincuente. ${ }^{55}$

9. El capítulo décimo (Del abuso de la penalidad) quizá sea el más interesante del libro, pues demuestra que siempre que hubo poder punitivo hubo abuso del mismo, o sea, que el abuso es una nota estructural y no conyuntural del ejercicio del poder punitivo. Si es propio del hombre abusar en general de todas las cosas, justo es reconocer que la sociedad, que se atribuyó el derecho de punir, en ningún tiempo ni en ningún país se ha mostrado más prudente que éste. ${ }^{56}$ No se refiere aquí a la ferocidad de las penas, o sea, al abuso en cuanto a su magnitud, sino en cuanto a los actos sometidos a ella. La sola historia de la intolerancia religiosa llenaría volúmenes, por lo que se limita a citar algunos ejemplos aislados,

\footnotetext{
51 Con gran frecuencia en esta materia cita a Charles Lucas, que era una de las más altas autoridades de su tiempo en la materia y que seguirá produciendo en años posteriores: del mismo, La récidive et le projet de rélégation des récidivistes, extrait du compte-rendu de l'Académie des Sciences morales et politiques, 1883; idem, 1879.

52 Idem, p. 157.

53 Idem, p. 160.

54 Idem, p. 164.

55 Idem, p. 173.

56 Idem, p. 174.
} 
comenzando por la ley mosaica. Recuerda que se penaba con la muerte matar un buitre en Egipto, en Atenas el sacrilegio (caso Sócrates), en Roma las vestales que dejaban extinguir el fuego y a los cristianos, especialmente en decreto de Diocleciano, sometidos a la pena de alta traición, o sea, a ser quemados vivos (vivicomburium) o entregados a las bestias (damnatio ad bestias). Seguidamente recuerda las penas por blasfemias y otros sacrilegios y herejías, a Torquemada, las penas a los judíos por casarse con no judías o por hacerse servir por sirvientes no judíos, y la expulsión de los judíos de España. Sigue con los ejemplos y concluye que aún cuando el abuso de la penalidad no tuviese por testimonio irrecusable esa incompleta enumeración, sería absolutamente sancionado por todos los suplicios infligidos a innumerables mártires de su fe y de su opinión. ${ }^{57}$ Pasa a la persecución de la brujería y de la hechicería, que remonta a la propia ley mosaica (Maleficos non patieris vivere, cita el Éxodo), la sigue en los griegos, en Roma con la ley Cornelia y otras, pasa luego a la Europa medieval y moderna, para terminar con las penas impuestas a quienes por sortilegios atentaban contra la vida de los monarcas. ${ }^{58}$ A continuación pasa revista a las ridiculeces calificadas de crímenes de lesa majestad, desde la Roma imperial hasta Inglaterra. ${ }^{59}$ A cuántas penas y suplicios no habrá dado lugar la esclavitud, sin la cual Platón afirmaba que la sociedad no podría subsistir. Recuerda las leyes espartanas y las atenienses; respecto de estas últimas acota que el testimonio de los esclavos no era válido y que para compensar esta falla se apelaba a la tortura, la quaestio respondida bajo tortura por el esclavo tenía validez, ${ }^{60}$ lo que luego sucedería también en Roma. De inmediato pasa a recordar los poderes punitivos del pater familiae, las sanciones a los solteros y las penas a las prostitutas, condenadas a muerte en caso de reincidencia por San Luis. ${ }^{61}$ En cuanto al juego, señala que es la mejor prueba de la impotencia de las penas para contener las pasiones humanas. ${ }^{62}$ Recuerda la pena de muerte por la caza

$\begin{array}{ll}57 & \text { Idem, p. } 191 . \\ 58 & \text { Idem, p. } 204 . \\ 59 & \text { Idem, p. } 206 . \\ 60 & \text { Idem, p. } 208 . \\ & \\ 61 & \text { Idem, p. } 216 . \\ 62 & \text { Idem, p. } 217 .\end{array}$

Revista Seqüência, no 59, p. 193-218, dez. 2009. 
ilegal, las penas a los suicidas, las penas por usar tabaco en Rusia, Turquía y Persia, ${ }^{63}$ las del contrabando, y con referencia a este último reproduce una frase de Blanqui, de considerable actualidad: Los ciudadanos no deben impuestos sino al estado. Cuando vosotros obligais a un hombre a comprar una camisa o una sábana bajo el imperio de la prohibición, le imponeis una tasa en beneficio de un fabricante que no le proporciona nada en cambio. ${ }^{64}$ Para quienes pueden creer que la severidad de las penas contendrá a quienes falsifican sellos, recuerda las terribles penas amenazadas en los siglos XVII y XVIII, como también para el contrabando. ${ }^{65}$ Se refiere también a las penas atroces para otras conductas: al duelo; a quien no declare a qué partido pertenece; a la calumnia; al montaje de una pieza de teatro; a la condena a perder el instrumento del crimen; a las ejecuciones de toros homicidas en 1313 y 1499; a la excomunión de las orugas en 1516; a Gaspar Baillly, que en el siglo XVI publicó una obra sobre los procedimientos contra animales ${ }^{66}$ y su técnica de defensa. Señala que la omisión de delatar, que honra al hombre, ha sido en todo tiempo y país materia de las más graves penas. ${ }^{67}$ Asi fue en Francia incluso en el código de Napoleón y hasta 1832, para quien no denunciase crímenes de lesa majestad y complots. Recuerda las prohibiciones de la Convención para los emigrados, ${ }^{68}$ los límites al lujo (sanciones al número de sirvientes o de animales o por comer ciertas viandas, llevar ciertas prendas, construir una habitación nueva en la casa, etc). Evoca que los primeros impresores alemanes que llevaron libros a París fueron condenados como brujos y se salvaron huyendo ${ }^{69}$ y la no menos interesante prohibición de la enseñanza de otra lógica que no fuese la aristotélica, ${ }^{70}$ restaurada en la Argentina dictatorial. Concluye del siguiente modo: Después de haber leído estos principios tan incompletos, cómo podría no convenirse en que los anales

\footnotetext{
63 Idem, p. 220.

64 Idem, p. 221.

65 Idem, p. 222.

66 Idem, p. 227.

67 Idem, p. 226.

68 Idem, p. 228.

69 Idem, p. 235

70 Ibidem.
} 
de la penalidad testimonian, más que la ignorancia y la perversidad de los pueblos, la estupidez y crueldad de los gobernantes. Pero lo que prueban, más allá de la arbitrariedad de la pena, es su impotencia. ${ }^{71}$

10. Después de rechazar por absurdas las llamadas penas específicas, o sea, el corte de la mano al ladrón, de la lengua al blasfemo, etc. (capítulo undécimo, De la especialidad de las penas), ${ }^{72}$ comienza el capítulo siguiente (De la eliminación penal) con una observación que conserva plena actualidad: Lo que caracteriza el progreso penal, mucho más que la mitigación de las penas, es la sucesiva impunidad de actos que eran considerados crímenes o delitos, como también su determinación más exacta, más precisa, más fundada en la verdad, o sea, en definitiva, su eliminación. ${ }^{73}$ Conforme a este criterio las actuales tendencias de la legislación penal en el mundo serían claramente regresivas, como lo señalan los autores que aún se mantienen en líneas liberales de pensamiento.

Girardin recuerda que los anales de los países más civilizados están repletos de condenas extremas y crueles por brujería y sortilegios, como también a personas que creyeron que tenían la libertad de pensar y de expresarse, y más recientemente los llamados delitos de prensa. Se pregunta quién será culpable por esas condenas, si los condenados o los jueces, y concluye que es tiempo de salir finalmente del laberinto penal en que la sociedad ha extraviado a la humanidad durante siglos. ${ }^{74}$ Afirma que para ello debiera comenzarse por eliminar los delitos que sólo existen en la imaginación de los pueblos ignorantes y de legisladores atrasados; en segundo lugar, debieran cancelarse las numerosas e innecesarias distinciones en la escala penal. Afirma que de este modo disminuirá el número de malhechores que la represión ha producido y la experiencia penitenciaria testimonia, porque la pena jamás ha corregido a otros que a quienes se hubiesen corregido sin ella, por el retorno de su conciencia ausente; sostiene que, por el contrario, la pena

\footnotetext{
71 Idem, p. 236.

72 Idem, p. 241.

73 Idem, p. 242.

74 Idem, p. 244.
} 
muchas veces lo ha impedido. La represión - afirma - es una almohada sobre la cual la sociedad ha dormido demasiado tiempo. Si tarda en despertar, será deglutida por la revolución que mina el suelo sobre el que descuidadamente construimos nuestras moradas, revolución implacable, a la que sólo podremos escapar adelantándonos mediante una reforma radical, uno de cuyos primeros términos debe ser la reforma penal. Es ciego quien no ve que las prisiones que nos tranquilizan son los cuarteles que nos amenazan. ¿Cuál es el primer acto de las multitudes victoriosas? ¿No es acaso dar libertad a los detenidos, incorporarlos a sus filas y a veces tomarlos como jefes? No teniendo nada que perder, arriesgan todo; no hay exceso alguno, se ha visto, ante el que se detengan. ${ }^{75}$ Afirma rotundamente que el tiempo de la represión legal ha terminado y ha llegado el tiempo de la eliminación penal. Esta eliminación no será demasiado rápida ni demasiado radical. Hasta el día de la abolición definitiva de toda pena corporal, de todas las penas diferentes de la publicidad penal y de la multa proporcional a la fortuna certificada por el impuesto transformado en seguro, no deberá haber más que un único crimen, el homicidio, y una única pena, la muerte. ${ }^{76}$ A continuación demuestra cómo varios conflictos criminalizados podrían resolverse sin la punición; si bien algunas de las soluciones son simplistas, otras conservan amplio sentido: la corrupción de funcionarios públicos se previene mediante un control eficaz que la haga poco menos que imposible; si los arrestos ilegales son todavía posibles, es por culpa de la sociedad. En cuanto al robo, razona que después de abandonar la persecución de los herejes en Francia el número de protestantes disminuyó, lo mismo que el de brujas y hechiceros y, por último, observa que cuando el poder punitivo se interrumpe violentamente después de cada revolución, lejos de aumentar, los homicidios y los robos disminuyen. ${ }^{77}$

Sostiene algo que parece verificarse en nuestra realidad cotidiana: una sociedad ofrece más seguridad cuantas menos leyes penales tiene ${ }^{78} \mathrm{y}$ aunque no cree que pueda desaparecer el poder puntivo muy rápidamente, de

$\begin{array}{ll}{ }_{75} & \text { Idem, p. } 245 . \\ 76 & \text { Idem, p. } 246 . \\ { }_{77} & \text { Idem, p. } 250 . \\ 78 & \text { Idem, p. } 251 .\end{array}$ 
cualquier manera confía en que se medite sobre ello a partir de dos grandes fallas que produce la punición, que son los liberados y los reincidentes. ${ }^{79}$ Girardin no percibía que el sistema penal provoca reproducción porque necesita clientela para autoalimentarse, pero dio en el clavo sobre el fenómeno mismo de la reproducción clientelar. En palabras de su tiempo, dado que el problema de los liberados no tiene solución, siguiendo a Montesquieu afirmaba que un buen estado debe dedicarse más a prevenir el crimen que a castigarlo, concluyendo por ello que todas las penas corporales deben desaparecer, ${ }^{80}$ excepto la de muerte, cuya desaparición reservaba para el final, porque no era reproductora.

11. En el capítulo décimotercero (De la atenuación de las penas), dice que la atenuación de las penas, su corta duración, pueden seducir a los que creen que tienen el poder de enmendar al culpable, pero se trata de una ilusión que no será compartida y que rechazarán los que apoyan en el estudio profundo de los hechos la firme convicción de que las penas, sean cuales fueren, pervierten a los condenados en lugar de corregirlos. ${ }^{81}$ Cita varios autores que ponen de manifiesto que el estado moral de la Francia del tiempo de las penas crueles no era superior a su propio tiempo. ${ }^{82} \mathrm{Si}$ bien cree que la atenuación de las penas es positiva desde el punto de vista de la humanidad, de la sociedad y de la moral, como un real progreso penal, pero no por ello debe creerse que son más eficaces que las penas crueles, o sea, que concluye que ninguna de ambas tiene eficacia. ${ }^{83}$ El gran problema que Girardin plantea a la intervención punitiva es lo que la sociología del siglo XX llamó desviación secundaria: su gran problema es el liberado, al que llama soldado de todas las revoluciones, ${ }^{84}$ que representa un peligro mayor al egresar que al ingresar a la prisión, lo que reafirma con numerosas opiniones. Si es cierto que la liberación conduce a la reincidencia, si es verdad que la punición corporal se convierte

\footnotetext{
79 Ibidem.

80 Idem, p. 254.

81 Idem, p. 255.

82 Idem, pp. 256-260.

83 Idem, p. 260.

84 Idem, p. 261.
} 
en escuela de perversión y revolución, para que cese de ser escuela de crueldad y tiranía, debemos frenarla. ${ }^{85}$

12. Después de haber concluído la crítica deslegitimante del poder punitivo en el libro primero de su obra, Girardin dedica el libro segundo a la construcción, es decir, a imaginar la sociedad sin penas corporales. El capítulo primero de este libro segundo (De la publicidad penal) está dedicado a demostrar cómo las sanciones sociales pueden reemplazar adecuadamente y con mucha menor artificiosidad y mayor beneficio a las penas formales. Libertad humana y penalidad corporal son dos términos que se excluyen; pero si bien hay incompatibilidad radical entre libertad indivisible y penalidad legal, no la hay entre la libertad indivisible y la publicidad penal. ${ }^{86}$ La publicidad es el presupuesto necesario para que funcionen las sanciones sociales, que serían las verdaderas penas naturales. Existen muchos actos sociales - dice Girardin - que son sancionados con el desprecio, el odio, la miseria, la ruina, la desconsideración, y que no son materia de conocimiento de los jueces. En otras palabras: propone una publicidad que libra los conflictos a las sanciones sociales. La penalidad que propongo no es una penalidad inventada, no tiene nada de arbitrario, es la consecuencia inherente a la acción misma, es a esta acción lo que la sombra al cuerpo, es lo que debe ser, es la publicidad, nada más ni nada menos. Como la gravedad es una ley, la publicidad también lo es. La publicidad es al orden social lo que la luz al orden físico. ${ }^{87}$

Ante la inevitable objeción de que sin penalidad formal crecería la criminalidad, sostiene firmemente y con gran modernidad que criminalidad y penalidad son dos términos independientes, ${ }^{88}$ lo que prueba con múltiples datos de su tiempo. La independencia de ambas variables es, pues, una verificación nada nueva $\mathrm{y}$, sin embargo, siempre negada en el discurso jurídico penal.

Para instrumentar la publicidad Girardin proponía un registro de vida, que era una suerte de carta que debía llevar el ciudadano, donde se

${ }^{85}$ Idem, p. 272.

${ }^{86}$ Idem, p. 275.

${ }^{87}$ Idem, p. 285.

${ }^{88}$ Idem, p. 280. 
consignaba todo el curso de su existencia y se marcaban las condenas. Era una suerte de registro de deudores morosos bastante impracticable en su tiempo. El libro trae una página desplegable con el modelo que el autor imaginaba para consignar los datos, por cierto que sumamente ingenuo. Supone que se le acusará de querer reponer la marca a fuego y se defiende diciendo que sería una marca transformada por la civilización y excluyendo la barbarie. Se pregunta qué mal habrá en que quien tenga manchado su registro de vida reciba la sanción social correspondiente. Cita a Montesquieu y a Rousseau en apoyo de la eficacia de su propuesta y termina preguntándose: $Y$ dando por única respuesta al crimen cometido el crimen inscripto ¿qué hará la sociedad? Y responde que al sujeto le reprochará la familia, la comunidad, el lugar de su nacimiento, todos, y no podrá eludir este reproche como no puede eludir su sombra. ${ }^{89}$ Reconoce que de alguna manera está proponiendo el restablecimiento de la pena de exilio voluntario, o sea, la exclusión de la sociedad. Los únicos hechos que dejaba de momento fuera de su propuesta de señalar con un sistema de registro las faltas en forma pública y dejarlas libradas a las sanciones sociales, eran los homicidios, para los que proponía mantener transitoriamente la pena de muerte hasta que también se la pudiese hacer desaparecer, teniendo en cuenta que observaba la caída de su frecuencia en Francia.

En este aspecto, la posición de Girardin era sumamente interesante, pues partiendo de una realidad de escalas penales que era coronada con la pena de muerte por asesinato, se oponía a que la abolición comenzase por la pena de muerte, invirtiendo el planteo, o sea, proponiendo que se eliminasen las restantes penas corporales y luego recién se eliminase la de muerte. Para ello se expresa de un modo que la criminología habrá de rescatar para presentarlo como innovador con la crítica sociológica a las instituciones totales de los años sesenta del siglo $\mathrm{XX}$ y, sobre esa base caracteriza de esta forma ese momento transitorio previo a la desaparición de la pena de muerte: La experiencia prueba que todo sistema penitenciario, sea cual fuere, desmoraliza a los guardianes, los hace crueles y tiránicos, sin moralizar a los detenidos, que los hace

${ }^{89}$ Idem, p. 299. 
cínicos e hipócritas. Evidentemente, eso no será aún la sociedad sin penas corporales, pero indudablemente será un inmenso paso adelante hacia la sociedad del año 1900, hacia una sociedad en la que no haya más penalidad que la publicidad penal y que la penalidad pecuniaria suceda a la penalidad legal y a la penalidad corporal. De todas las fuentes de depravación, se habrá suprimido la más gruesa; de todas las escuelas de tiranía y de crueldad, se habrán cerrado las más peligrosas. ${ }^{90}$

13. En el segundo capítulo de este libro segundo (La sociedad sin penalidad corporal) Girardin trata de mostrar cómo debería reorganizarse la sociedad en que las penas desapareciesen. Si de los testimonios que he acumulado resulta que, sea que se las agrave o que se las atenúe, las penas vigentes son todas ineficaces, todas son igualmente impotentes, sea que se propongan enmendar al condenado, sea que se propongan intimidarlo, la consecuencia que extraerá la lógica es que conviene buscar una via diferente de la que la sociedad ha seguido durante tantos siglos obstinándose en marchar en sentido contrario a la humanidad. ${ }^{91}$ Según Girardin, el error de la sociedad - que a fuerza de repetirlo se ha convertido en una verdad fuera de discusión - es que concentrando a un grupo de personas consideradas peligrosas por sus naturalezas perversas, los neutraliza, cuando en realidad no ha hecho más que aumentar el peligro y reproducirlo. Sostiene que debe hacerse exactamente lo contrario, o sea, distribuirlo para que se pierdan entre la totalidad inmensamente superior de la población. Para ello deben ser colocados bajo la vigilancia de su familia pecuniariamente responsable, pero sobre todo, de la comuna de nacimiento (comuna materna). Es extraordinariamente moderna la concepción de Girardin respecto de las funciones de la comuna. Parece increible, pero en 1871 define la función del estado de bienestar, sólo que en manos del municipio. Visionariamente vaticina su fracaso en manos del estado centralizador, al que considera un obstáculo que todo lo complica, y revalora la función del municipio: Se trate de condenados, de liberados, de alienados, de niños abandonados, de inválidos de trabajo o de obreros privados de trabajo por causas independientes de su voluntad, se trate de todos esos o de otros problemas sociales, no hay ninguno que, después de

$\begin{array}{ll}90 & \text { Idem, p. } 318 . \\ 91 & \text { Idem, p. } 320 .\end{array}$ 
la familia, no pueda resolver la comuna normal. ${ }^{92}$ Aclara que en esto es fecunda la idea del falansterio, pero precisa más adelante que no se afilia a la concepción del socialismo utópico en esta variante, sino que reclama de la comuna que asuma su real función municipal y nada más. ${ }^{93}$ Embate contra la centralización estatal y sostiene que el estado centralizador es un estado condenado a trabajos forzados. ${ }^{94}$ Por ello postula una comuna libre en un estado libre, en que éstas serían los eslabones de una cadena (que sería el estado). Calcula que en Francia se requerirían unas cinco mil comunas. Muestra con números cómo se resolvería el problema penitenciario, pues cada comuna debiera hacerse cargo sólo de un puñado de presos, no superior a diez en total. ${ }^{95}$ Acabarían con ello los vicios de la concentración y sobrepoblación penal. Rechaza la idea del patronato después de la liberación y reclama que éste intervenga antes de la prisión y en reemplazo de ellla, no cuando ya se ha hecho el mal y es dificil de remediar. ${ }^{96}$ Resuelve la cuestión financiera del estado de bienestar comunal que propone mediante una reforma al código civil, que hace a la comuna madre heredera de la parte de un hijo de todos sus habitantes, como forma compensatoria de las nuevas tareas de que la inviste. ${ }^{97}$ De esta manera se propone atacar en su origen el mal que causa los robos y los homicidios, impidiéndolo antes que nazca: se trata de suprimir en su fuente la ignorancia y la miseria. ${ }^{98}$ Si esta idea fuese falsa no sería verdad que la criminaldad que cae bajo los golpes de los tribunales y de la policía sea más rara entre los que saben leer y escbir que entre los que no saben, entre los que razonan que entrre los que no razonan, entre los que tienen bienestar que entre los que no lo tienen. ${ }^{99} \mathrm{~A}$ continuación define con todas las palabras el ideal del estado de bienestar, sosteniendo que con los adelantos técnicos y administrativos del estado y

\footnotetext{
92 Idem, p. 322.

93 Idem, p. 324.

94 Ibidem.

95 Idem, pp. 326 y ss.

96 Idem, p. 335.

97 Idem, p. 336.

98 Idem, p. 338.

99 Idem, p. 339.
} 
de la economía, es inconcebible que haya un solo adulto iletrado, un solo habitante no asegurado contra todas las contingencias, sin la certeza de los medios que le permitan el acceso al bienestar, entre los cuales el trabajo y la probidad exijan los menores esfuerzos. A medida que el trabajo resulte menos penoso el robo se volverá más raro ${ }^{100} \mathrm{y}$ con el enrarecimiento del robo disminuirán los riesgos de homicidio.

Girardin considera que la sociedad sin penas corporales debe educar para la solidaridad y dejar de formar militares para matar, y asi como educa para el valor debe hacerlo para la honestidad. No propone la prohibición alcohólica, sino que afirma que dando la posibilidad de ir al café la gente dejará de ir al bar, sosteniendo rotundamente que el aumento del bienestar eleva el nivel de moralidad. ${ }^{101}$

14. Sostiene que una vez enunciado un principio debe tenerse el suficiente coraje para extraer de él todas sus consecuencias, sin eludir ninguna. Ese defecto lo observa en quienes admiten a cualquier título la penalidad corporal, sea como expiación o como retribución, como intimidación o como corrección, la admitem a medias, la admiten sin todo su rigor, siendo una inconsecuencia que se condena por la incertidumbre de sus tituveos y la multiplicidad de sus ensayos, todos condenados sucesivamente por la experiencia, tanto en el nuevo como en el viejo mundo. ${ }^{102}$

Compara los riesgos de la guerra y de la conquista en cuanto a homicidios y robos con las probabilidades estadísticas de ser víctima en un hecho individual y concluye que las primeras son mucho mayores. ${ }^{103}$ Metafóricamente considera a la sociedad como una ciudad sitiada y aislada, en la que se llegaría a la antropofagia, pero en la medida en que eso deje de ser necesario desaparece; de la misma manera cree que desaparecerán los robos y los homicidios, como la civilización hizo desaparecer la antropofagia, y asi la civilización ocupará el lugar de la barbarie. Sostiene que a la sociedad incumbe la tarea de deshabituar al

\footnotetext{
100 Ibidem.

${ }^{101}$ Idem, p. 341.

102 Idem, p. 343.

${ }^{103}$ Idem, p. 344.
} 
ser humano al homicidio y al robo ${ }^{104} \mathrm{y}$ para ello propone: la extinción de la guerra; de la ignorancia general invirtiendo en educación el presupuesto de guerra; de la miseria inveterada y heredada; estableciendo la responsabilidad pecuniaria de los parientes en el mismo grado en que concurren a la herencia, la responsabilidad pecuniaria de la comuna madre en defecto de la familia, compensada por la herencia de la parte de un hijo; liberar al estado respecto de los crímenes y delitos, derivando su responsabilidad en las familias y en las comunas; transformar el impuesto obligatorio en prima de seguro que cubra todos los riesgos sociales; reemplazar al pasaporte por el registro de vida o póliza general y especial de seguro social; establecer la previsión social mediante retención de un centavo por hora de trabajo, llevada a cabo y depositada por el empleador; ofrecer créditos mutuales e inmobiliarios; reemplazar todas las penas existentes por multa, interdicción y muerte, hasta que se puedan hacer desaparecer también éstas. ${ }^{105}$

Insiste sobre la esclavitud penal: La extrema dificultad - o imposibuilidad - de reintegrar a los liberados a la sociedad que los rechaza sin piedad, que los golpeó, los marcó a fuego, los aprisionó, los lanzó a la miseria perpetua impidiéndoles levantarse, esta imposibilidad es la condenación soberana a la servidumbre penal. ${ }^{106}$ Es obvio que llama servidumbre penal al resultado de la función reproductora del sistema penal. Frente a ello, afirma que la esclavitud de la pena corporal no puede subsistir. Todo lo que se diga a su respecto será tan falso ocmo lo que dijo Aristóteles cuando declaraba que no podía existir una sociedad sin la esclavitud de su tiempo. ${ }^{107}$ Sin embargo, la esclavitud antigua y la servidumbre feudal desaparecieron sin llevarse a la sociedad con ellas, por lo que tiene plena confianza en una sociedad sin penas corporales, que será una sociedad muy dinámica y apta para salvarse de una revolución moderna, que no se llevaría a cabo con las armas sino con los votos. Expresa que así como es tarde gritar iAl fuego!, cuando éste todo lo devoró, sería muy tarde gritar iA la ignorancia, a la miseria! cuando

\footnotetext{
${ }^{104}$ Idem, p. 349.

${ }^{105}$ Idem, pp. 351-355.

${ }^{106}$ Idem, p. 361.

107 Ibidem.
} 
los liberados, reincidentes y otros hayan destruído todo llevados por la ignorancia y la miseria. ${ }^{108}$

Girardin se pregunta: ¿Puede subsistir la sociedad sin el derecho de punir? En otros términos ¿Puede sustituir la cultura del hombre por el hombre a la punición del hombre por el hombre, que sólo es posible por la dominación del hombre sobre el hombre? ${ }^{109}$ Para ello propone suprimir el entrenamiento militar, acabar con medio millón de hombres desfilando con armas en la mano y entrenados para responder al grito de fuego matando a un semejante, conservando sólo la gendarmería, sustituyendo el reclutamiento corporal por el reclutamiento intelectual, el espíritu de rivalidad por el de reciprocidad, la paz armada por la paz asegurada, el nacionalismo por el racionalismo, a la vieja política internacional por la política intercomunal. ${ }^{110}$

Girardin estaba firmemente convencido de que el poder punitivo desaparecerá, como han desaparecido otras cosas que en su momento parecían consustanciales a la propia sociedad. Ni el poder paterno, ni el marital, ni el doméstico, ni el público, ni la misma penalidad son hoy lo que fueron en los tiempos que acabo de recordar sumariamente, y hoy nos parecen increíbles atrocidades lo que entónces eran consideradas penas justas y legítimas necesidades por hombres como Cicerón y Tácito y por jurisconsultos como Paulo y Ulpiano. ${ }^{111}$ Recuerda más adelante la crítica de Fachinei al libro de Beccaria ${ }^{112}$ y en la respuesta de Muyard de Vouglans en 1780 a la crítica de este autor a la tortura, ${ }^{113}$ y observa lacónicamente que nueve años después de esa obra estalló la revolución.

\footnotetext{
${ }^{108}$ Idem, p. 362.

${ }^{109}$ Idem, p. 367.

${ }^{110}$ Idem, p. 369.

${ }^{111}$ Idem, p. 377.

${ }_{112}$ V. Cesare Beccaria, Dei delitti e delle pene, con una raccolta di lettere e documenti relativi alla nascita dell'opera e alla sua fortuna nell'Europa del Settecento, A cura di Franco Venturi, Giulio Einaudi Editore, 1981, p. 164.

${ }^{113}$ Se está refiriendo a una edición posterios de la conocida obra de Pierre-François Muyard de Vouglanns, Institutes au Droit Criminel, ou Principes Géneraux sur ces matieres, suivant le droit civil, canonique, et la jurisprudence du Royaume: avec un traité particulier des crimes, París, 1757.
} 
Recuerda la derogación de la tortura en 1780 y los esfuerzos posteriores por erradicar todas sus manifestaciones y revisar las ordenanzas de $1670,{ }^{114}$ que provocaron el rechazo de los jueces (llamados parlamentos). Y concluye con el siguiente párrafo: La tortura, el descuartizamiento, y toda la variedad de suplicios sin los cuales parecía que la sociedad no podía subsistir, han desaparecido. Hoy ya no se vierte plomo derretido ni resina hirviente en las heridas del paciente, y sin embargo la sociedad subsiste, como continuará cuando hayan desaparecido la prisión, la reclusión, la detención, los trabajos forzados perpetuos y temporales, la deportación y, por fin, en el primer año del próximo siglo, la pena de muerte. ${ }^{115}$

15. En el tercer capítulo, finalmente, el autor apela a la controversia. Reconoce sus limitaciones, considera la posibilidad de superación de las guerras, lamenta que Bismark haya desatado la guerra con Francia, muestra la Comuna de París como un hecho lamentable a punto de quemar todo París, y, finalmente, llama a la controversia para debatir la idea que lanza en el libro.

Nos hallamos frente a un autor que puede ser considerado un adelantado del estado providente, que en 1868 - antes de la Comuna de París y horrorizado después de ésta -, adopta el camino que se llamaría reformista y prevé que el futuro estado de bienestar, gestionado por los municipios y no por los estados nacionales, habrá de hacer desaparecer las penas corporales y con ello disminuirán los delitos. Aunque eso no haya pasado tan rápidamente como Girardín pretendía (conforme a su cronología las penas podían desaparecer más o menos rápido y la pena de muerte remanente en 1901), a ciento treinta años de distancia no puede negarse que una parte de lo previsto ha sucedido: el estado de bienestar llegó en algunas regiones del planeta, aunque no se extendió al resto. En esa parte del planeta, el estado de bienestar hizo desaparecer la pena de muerte y contraer notoriamente las restantes penas corporales. Pero no por ello desapareció totalmente el poder punitivo y, más aún, finalmente

\footnotetext{
${ }^{114}$ Sobre ellas: Nouveau Commentaire sur l'Ordonnance Criminelle du mois d'Août 1670, Parìs, 1769.

115 Idem, p. 387.
} 
tiende a reducirse y a desaparecer el propio estado de bienestar, con la consiguiente nueva tendencia expansiva del poder punitivo, que retoma las características que Girardin daba por superadas con el liberalismo limitador de Beccaria.

La obra de Girardin es la obra de un auténtico abolicionista y también de un político. No es un utópico ni un revolucionario al viejo estilo, sino un liberal progresista que sueña el estado de bienestar o estado providente municipalizado. La virtud de su obra es que deslegitima al poder punitivo de modo claro, con los mismos argumentos que casi un siglo y medio después continúan siendo innegables. Su táctica de hacer desaparecer la prisión primero y la pena de muerte luego es la de un político: conservaría por un tiempo la pena para los delitos que producen más alarma (era el primer periodista de gran tirada). Su error consistió en no advertir lo que más de un siglo después señaló Foucault: la conservación del sistema penal no interesa porque prevenga nada, sino por la forma del poder que ejerce y que se traduce en vigilancia de toda la población. El interrogante que queda es el siguiente: cuando hoy la tecnología electrónica permite llevar a cabo la publicidad que preconizaba Girardin en forma mucho menos ingenua y muchísimo más efectiva, cabe preguntarse si este medio de control y vigilancia no tenderá a reemplazar al sistema penal y, también, si este control no será mucho más represivo que el propio control punitivo o si no logrará simbiotizarse con éste e incrementar niveles de represión. Es sugestivo que una de las garantías más discutidas de nuestros días sea el derecho la privacidad ante el increible avance de la publicidad.

Enviado em: 06/2009

Aprovado em: 10/2009 